\title{
PERSONAL CHANGE OF SOCIAL WORK STUDENTS THROUGH ESTABLISHING THE RELATIONSHIPS IN PROFESSIONAL PRACTICE
}

\author{
Ramune Bagdonaite-Stelmokiene \\ Kolping University of Applied Sciences, Lithuania \\ Vilma Zydziunaite \\ Vytautas Magnus University, Lithuania
}

\begin{abstract}
The article presents the results of qualitative research carried out with 53 social work students in Lithuania. The research focused on the personal change in social work students taking place during the professional practice in which students establish relationships with different participants in the practice. The use of unstructured reflection as a data collection method enabled students to remember, think over and put their practice experiences in writing. The data were analysed by applying grounded theory (Strauss \& Corbin, 1990). Findings revealed that social work students differently experience the establishment of relationships in the professional practice. These experiences lead to students' professional growth and personal change. The findings provide an opportunity to deepen the knowledge about students' experiences of relationships. These new experiences can promote students' self-awareness, the change of worldviews, beliefs and values as well as adding the new trends for the analysis of goals in professional practice of social work.
\end{abstract}

Keywords: client, personal change, social work, student.

\section{Introduction}

Social work students do not only enhance their professional competences during the practice period but they develop, change and grow as personalities. The practice constructs a new experience of interpersonal relations with different participants in the practice. During the practice students experience various emotional trials, rethink their fundamental values, identify and gain a better understanding of their strengths and weaknesses, and get to know themselves better (Litvack, Mishna \& Bogo, 2010; Raudeliunaite, 2010). Thanks to such an experience in interpersonal relations, students' personal change takes place: their values, attitudes and beliefs change; they rethink their future goals.

The personal change of social work students takes place during the practice by reflection on the experience acquired and by applying it in one's personal and/or professional domain. The reflection on the experience of learning and relationships enables students to become aware of what they have gained, to get to know themselves better, to take appropriate decisions and to provide effective social assistance to clients (Urdang, 2010).

In pursuit of positive professional relationships with clients and employees and positive practice results, the importance of self-awareness and the conscious 
use of self of the social worker (and the social work student) is highlighted (Neuman \& Friedman, 1997; Heydt \& Sherman, 2005). It was revealed that by experiencing various emotions in their relationship with clients and practice supervisors during the practice, social work students develop their selfawareness (Barlow \& Hall, 2007; Litvack et al., 2010); that the experience of relationships with various social actors in the practice influencing student's personal and professional self-perception is formed (Fortune, McCarthy \& Abramson, 2001; Raudeliunaite, 2010). However, it is not clear how the personal change of social work students takes place during their professional practice and how the personal change is influenced by different relationships with clients and employees.

The aim of the study is to describe the personal change of social work students by revealing students' subjective experiences in their professional practice.

In the article the concept of 'personal change' is described on the basis of literature review.

\section{The concept of 'personal change'}

Personal change includes the reorientation of personal attitudes, worldviews, values, beliefs and ways how individuals perceive their roles in different contexts (Young, 2013). An individual's awareness and a certain disciplined commitment to self-reflection and contemplation about the values and purposes of one's life, and perception of relationships between oneself and the environment, are required for personal change to commence (Chawane, Vuuren \& Roodt, 2003).

Personal change occurs by reflecting on the experience acquired when individuals transfer and adapt their new learning experience to their personal or professional life (Young, 2013). Reflection on one's learning experience enables the awareness of what has been acquired and leads to personal change (Neuman \& Friedman, 1997). By reflecting on their experiences during the practice and rethinking their values and goals, social work students learn and enhance their awareness of what they have experienced by recognizing their professional and personal development - all that leads to a professional performance of higher quality (Urdang, 2010). Students' personal change occurs in the course of the practice through re-evaluation of oneself as a personality and as a future social worker: self-awareness, self-testing or self-overcoming in new troublesome situations, and the acquisition of new experience (Raudeliunaite, 2010).

The transformation of worldviews, beliefs, skills and knowledge (including personal change) is contextual; it occurs in a certain place and at a certain time because it is through the socio-cultural context that individuals continuously experience various social interactions with the people around them (Young, 
2013). The organization has to create a reliable and safe learning environment ensuring psychological conditions for individuals to develop and change (Chawane et al., 2003). The practice organization of social work students, its organizational culture, and communication with the staff and clients, influence students' personal change, help them identify and perceive their personal and professional strengths and weaknesses. Facing different actors in the practice, students learn new concepts of worldview. This encounter affects students' learning as well as their personal and professional development (Litvack et al., 2010).

Personal change takes place as an inexhaustible source of change in all other fields. If an individual is not compassionate and disregards the needs of others, he/she will not be capable of effective action in a caring society (Edwards \& Sen, 2000). Social workers (and social work students) themselves are like instruments in the process of social assistance; it is therefore important to know oneself well in order to construct adequate and effective social assistance relationships with clients. The personal values, attitudes and beliefs of social workers directly and indirectly affect how helpful they can be to their clients (Heydt \& Sherman, 2005). Hence, a conscious use of self of the social worker (and the social work student) is appreciated in the social assistance process. The awareness of one's feelings, motives and skills as well as excellent expertise are essential for effective self-application in the provision of assistance. Good self-awareness enables the creation of effective interpersonal relationships between the social worker (or the social work student) and the client (Neuman \& Friedman, 1997). The self-awareness of social work students is developed in the course of professional practice (Litvack et al., 2010). Students must be able to identify and understand their feelings, attitudes and relationships with clients in order to help them effectively (Urdang, 2010). Not only the student's professional skills and knowledge but also his/her selfawareness and self-acceptance are important in communication with clients (Reupert, 2009).

Supervision or consultation provided by practice supervisors may add to the personal change of social work students. They may act as a mirror for students by reflecting the experiences of their relationships with the clients and the staff. Self-reflection may also protect students from professional burnout and troubles in setting the boundaries of communication with clients (Urdang, 2010). The reflection and awareness of the experience acquired lead students to selfgrowth and new self-discovery. Self-exploration and self-reflection in communication with people enable a better perception of different personal worlds by simultaneously changing students' beliefs, views and values, and enabling their development and growth. 


\section{Research methodology}

Research design. In order to understand how the personal change of social work students takes place during their professional practice by revealing students' subjective experiences, a qualitative research design was applied (Creswell, 2003).

Sample. A targeted convenience sample was applied. The research participants comprised fifty-three final-year social-work students from one university of Applied Sciences upon completion of their long-term (3-month) professional practice.

Methods. Unstructured written reflection was applied for data collection. Reflections were put in writing upon students' return from their long-term professional practice where they worked with specific social work cases. A grounded theory method (Strauss \& Corbin, 1990) was applied for data analysis through the use of open, axial and selective coding. The categories that derive from the collected data were constructed by means of open coding. Axial coding was used to identify the relationships between the categories formed in the stage of open coding by identifying the necessary conditions, context, strategies, interactions, intervening factors, and consequences. In the course of selective coding the core category was identified; the categories formed in the course of axial coding were integrated and the relationships with it were established.

Ethics. The research complied with the following principles of research ethics (Orb, Eisenhauer \& Wynaden, 2001):

- autonomy - research participants had a right to express their experiences through written reflections freely and could freely decide on their participation in the research;

- $\quad$ beneficence - research participants were presented the research aim and purpose; the data provided inflicted no harm on research participants;

- confidentiality - no information disclosing the identity of research participants was provided; research participants were associated with certain codes;

- $\quad$ justice - research participants had a right to ask about the research and to receive comprehensive information; the research sought no personal benefit; it relied on the principle of justice; the information provided by research participants was analysed in full.

\section{Results}

The core category - mutual attachment between the social work student and the client - was singled out in the analysis of experiences of relationships of social work students during their professional practice (Figure 1). The student's personal change takes place as part of this attachment. It is also influenced by the student's other relationships with different actors in the practice. It is namely 
the personal change of social work students during the professional practice that is presented in the article.
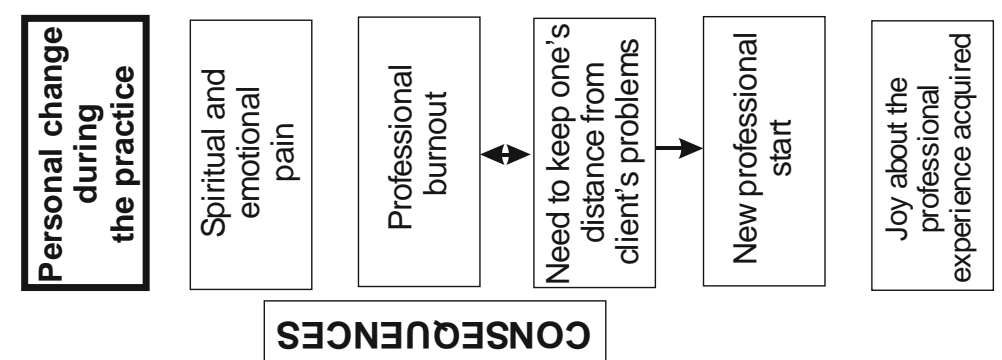

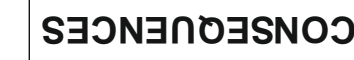
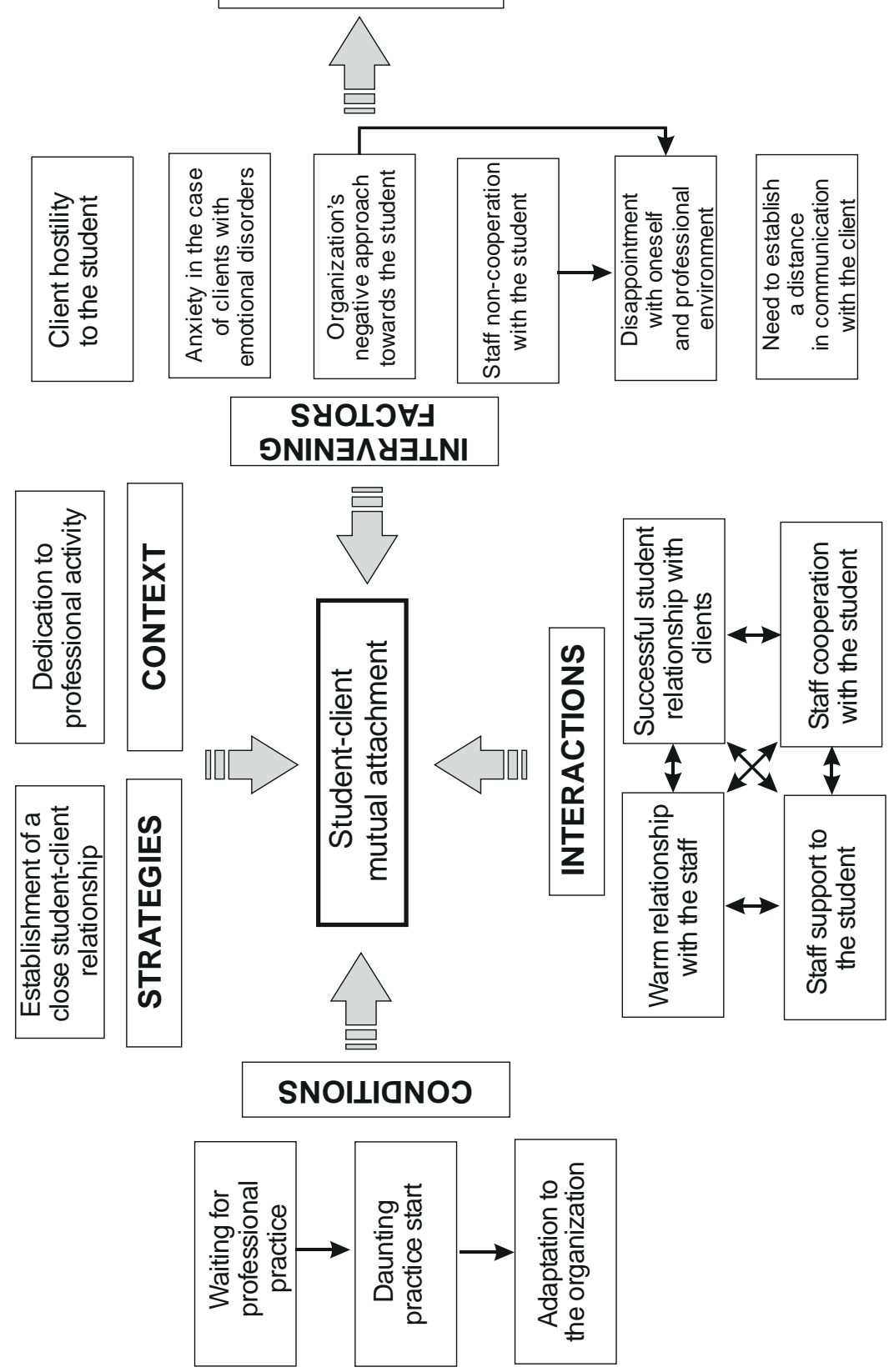

Figure 1. Personal change of social work students in professional practice through different relationships with clients and employees 
Before the beginning of their professional practice social work students live through the period of waiting which manifests itself in students' anxiety, uncertainty and constant thinking about the would-be practice. A wish to improve, to try oneself and a clear understanding what client group they wish to work with, what they are interested in, what learning experience they wish to acquire, ease the period of waiting for the practice. Such a conscious reflection on one's potential experience helps students understand their wishes and goals better.

Students gradually adapt to the practice organization and become a part of it: "once I reoriented myself and adjusted to the rules and order, I became a full member of the staff" (R11). Students get to know the organization's staff and clients and start "feeling how the work actually takes place in the organization" (R1). The unease and uncertainty about the future activity felt at the beginning of the practice disappear, and clarity ensues about the tasks and duties students will have to perform. They gradually acquire the confidence of the staff and the clients. Successful adaptation to the organization enables students to create warm and friendly relations both with the staff and the clients. A student becomes "sort of an insider among them" (R42).

When students establish close and confidence-based relations with their clients, their mutual attachment is gradually constructed. The new attachment experience influences students' personal and professional growth. Clients tend to open up to students to a greater extent; they tell students about their life and problems. This creates more opportunities for students to understand their clients better. The knowledge expands students' understanding about the individuals having gone through sorrowful experiences; it enables them to identify their attitudes and beliefs and rethink their current values. Students find out their personal properties necessary for communication with clients:

"the communication with the visitors of the centre requires knowledge as well as such personal qualities as discipline, for example, if you promise to pay a visit on a certain day, you must come if you wish to maintain the respect and confidence you have gained" (R24).

Students are not always successful in establishing warm relations with their clients. At the beginning of the practice clients do not trust students and communicate with them cautiously; they tell little about themselves and their problems. Students may even face violence from their clients. Under such circumstances students realize that they can also encounter dangerous situations in social work:

"while doing my practice, I actually realized why social work is assigned to dangerous professions. Somehow I did not understand what can be dangerous and difficult about it while studying. But after I myself faced violence from the children in foster care, I fully realized what it was all about" (R42).

While communicating with clients suffering from emotional disorders, students may be influenced by certain stereotypes: 
"I was so scared on my first contact with the client when I had to enter into a conversation with him. It was mostly due to my small store of knowledge on mental hospitals and various movies featuring people in straitjackets, unpredictable, savage and held in solitary confinement" (R5).

The encounter with such clients helps students identify and change their worldviews and beliefs, whereas the self-testing in new situations enables students to know themselves better: "it was very interesting to try myself in the sphere I have never tried before" (R20).

Students' personal change is also influenced by their relationships with the staff. Friendly relations between the student and the staff, with support and cooperation provided by the staff, help students take up their professional activity successfully and add to students' personal growth. The staff encourage students to focus on the achievement of their professional goals, help them not to give up in the face of initial difficulties and encourage them to be more selfconfident:

"throughout my whole life I have been very self-critical. Whatever I do, I always think I could do it better. My practice supervisor and the head of the institution noticed such a character quality of mine and advised me to trust myself more because I placed too high demands on myself. Taking into account the observations of other people and those of my own, I will try to develop greater self-confidence in the future" (R12).

However, hostile relations may also evolve between the students and the staff:

"for some reason we did not feel 'affection' and sympathy towards each other from the very beginning, and the relationship was not established. Even though, to say it vividly, we as if were in the same boat but at its different ends and preoccupied with our own concerns" (R42).

The staff may ignore students: "if you are a student, you don't deserve to be greeted" (R26). They may be uncooperative with respect to students, not share their experience and not provide any support. Hostile relations with the staff make students' learning and professional improvement more troublesome. Students start feeling disappointment with their professional environment and with themselves.

Students can suffer professional burnout during the practice. This manifests itself by confusion in the student's thinking as well as his/her values. Fear about one's professional activity and a sense of low self-esteem emerge. Students start feeling a continuous tension and an emotional collapse: "there were moments when I used to come back home and all I wanted was to cry and quit everything" (R45). Nevertheless, such an experience makes a profound contribution to the student's personal change. Students realize that it is necessary to create a certain distance from clients' problems, to learn not to bring those problems home, and that it is important "to work much with myself to be able do it" (R9). To avoid professional burnout, students realize that they need to change their approach. 
They gradually accept the fact that they are not capable of solving all the problems of their clients.

By reflecting on their experience, students realize that the practice enabled them to give sense to their lives. The practice helped them become stronger internally:

"earlier I used to be very sensitive about the children whose life went in the wrong direction (alcoholic parents who do not take care about their children; messy children belonging to a social risk group) but the practice made me stronger on the interior" (R6).

Students see their failures or mistakes in a positive light, believing that the failures and mistakes also contribute to their personal development:

"mistakes, as well, could not be avoided but I am convinced that they only made me stronger as a personality and showed more clearly that there is no limit to perfection, and if you want to work with clients, first of all, you have to learn to work with yourself" (R29).

The experience of different relationships in the practice allowed students to see themselves in a new light, to identify their strengths and weaknesses, to rethink their values, worldviews and beliefs; to realize their future goals, and to decide upon their professional choices.

\section{Discussion}

Social work students' personal change is influenced by the various social interactions during their practice. Students construct new experiences of interpersonal relationships with different actors in the practice. They become attached to their clients and undergo various experiences. A new experience of interpersonal relations gained during the practice enables students to take a look at themselves and their professional environment and to decide on their professional choice. Students' personal change manifested itself through increased self-awareness, the rethinking of one's values, the discovery of a new self and the analysis of the profession selected.

The relationship between social work students and clients, and the students' knowledge of clients' lives, provide an opportunity for students to rethink their values and beliefs (Barlow \& Hall, 2007; Litvack et al., 2010). Student-client relationships influence increased self-awareness of students as future social work specialists. The research results revealed that an open confidence-based relationship with clients enables students to identify their strengths and weaknesses. Close communication with clients helps students to know and understand better the lives of people who have lived through hurtful experiences. It changes students' worldviews, their perception about clients, their way of thinking and their values.

The relationship between the social work students and the practice supervisor during the practice influences their professional self-awareness, 
which is the basis for their professional self-identification (Raudeliunaite, 2010). Practice supervisors who rely on the "strengths perspective" in communication encourage students to identify their strengths and rely on them. Practice supervisors who share their experience, provide emotional support to students, give pieces of advice and encourage by simultaneously maintaining professional boundaries in communication with students, contribute to students' understanding of the selected profession of social work (Litvack et al., 2010). The research results revealed that the relationship with practice supervisors affects students' personal and professional development. The practice supervisor is seen as the key figure permitting students to reflect on their feelings and experiences. His/her consulting and feedback enable students to reflect on their learning experience and to know themselves better: to identify and accept their feelings, thoughts and experiences. Therefore, we can see a great need of supervision of social work practice for students.

Personal change and personal development are remarkably influenced by the culture of the organization in which the person is based (Chawane et al., 2003). In the course of the practice social work students communicate with both practice supervisors and other employees. When the relations with the staff are friendly and warm and communication takes place, a safe learning environment in the organization is created. If students sense hostility and non-cooperation from the staff, it causes them to have negative feelings and affects their personal life. Students experience feelings of low self-esteem and disappointment with their professional environment (Litvack et al., 2010). The research revealed that even a negative experience of relations with clients, practice supervisors or other staff of the organization makes students grow internally. Problem situations and encounters with the hostility of clients or employees during the practice enable students to get to know the peculiar characteristics of their profession. They learn from this experience, thus understanding themselves better. The reflection on the experience acquired enables students to identify both their professional and personal improvement. It may contribute to more effective professional performance in the future.

\section{Conclusions}

Social work students' personal change is influenced by their experience of interpersonal relations constructed during the professional practice. Different relationships with clients and an organization's employees are a valuable experience for students. This experience helps them acquire the awareness of their learning, rethink their future goals and get to know themselves better as personalities and as future professionals of social work. Such experiences determine the changes in students' values, beliefs, attitudes and worldviews. The creation of new interpersonal relations with different actors in the practice contributes to students' personal and professional growth. 


\section{References}

Barlow, C., Hall, B. L. (2007). "What about Feelings?": A Study of Emotion and Tension in Social Work Field Education. Social Work Education, 26(4), 399-413.

Chawane, T., Vuuren, L., Roodt, G. (2003). Personal Change as a Key Determinant of The Outcomes of Organisational Transformation Interventions. A Journal of Human Resource Management, 1(3), 62-76.

Creswell, J. W. (2003). Research Design: Qualitative, Quantitative, and Mixed Method Approaches. (2nd Ed.). Thousand Oaks, California: Sage Publications.

Edwards, M., Sen, G. (2000). NGO'S, Social Change and The Transformation of Human Relationships: A 21st Century Civic Agenda. Third World Quarterly, 21(4), 605-616.

Fortune, A. E., McCarthy, M., Abramson, J. S. (2001). Student Learning Processes in Field Education: Relationship of Learning Activities to Quality of Field Instruction, Satisfaction, and Performance Among MSW Students. Journal of Social Work Education, 37(1), 111-124.

Heydt, M. J., Sherman, N. E. (2005). Conscious Use of Self: Tuning the Instrument of Social Work Practice with Cultural Competence. TheJournal of Baccalaureate Social Work, 10(2), 25-40.

Litvack, A., Mishna, F., Bogo, M. (2010). Emotional Reactions of Students in Field Education: an Exploratory Study. Journal of Social Work Education, 46(2), 227-243.

Neuman, K. M., Friedman, B. D. (1997). Process Recordings: Fine-Tuning an Old Instrument. Journal of Social Work Education, 33(2), 237-244.

Orb, A., Eisenhauer, L., Wynaden, D. (2001). Ethics in Qualitative Research. Journal of Nursing Scholarship, 33(1), 93-96.

Raudeliunaite, R. (2010). Experience in Study Practice of Social Work Students: Analysis of Written Reflections. Social Work. Research Papers, 9(2), 48-55.

Reupert, A. (2009). Students‘ Use of Self: Teaching Implications. Social Work Education, 28(7), 765-777.

Strauss, A., Corbin, J. (1990). Grounded Theory Research: Procedures, Canons, and Evaluative Criteria. Qualitative Sociology, 13(1), 3-21.

Urdang, E. (2010). Awareness of Self-A Critical Tool. Social Work Education, 29(5), 523538.

Young, J. C. (2013). Understanding Transfer as Personal Change: Concerns, Intentions, and Resistance.New Directions for Adult and Continuing Education, 137, 71-82. doi: 10.1002/ace.200. 